\title{
INFORMATION TECHNOLOGY AND HUMAN FACTORS AFFECTING THE ACCURACY OF AUTOMATED PATIENT MEDICATION REPORTING SYSTEMS
}

\author{
Robert J. Boncella, Washburn University, bob.boncella@washburn.edu \\ Wenying Sun, Washburn University,nan.sun@washburn.edu \\ Carol Boncella, Lawrence Memorial Hospital, carol-boncella@sunflower.com
}

\begin{abstract}
This study aims to answer two research questions related to the implementation of one criterion of Meaningful Use - Active Medication List (AML): 1) What human factors affect the accuracy of the AML? 2) What information technology factors affect the accuracy of the AML? Since our study is exploratory and little literature was found on this topic, we conducted a case study to develop a theory that we can empirically test later. Through interviews, user manuals, and our own examination of the EHR system, we developed a research model and identified four factors affecting the accuracy of AML: List Taker, List Source, System Connectivity, and User Interface Design. The first two are human factors, and the last two are technology factors.
\end{abstract}

Keywords: case study, information system design, EHR software, meaningful use, active medication list

\section{INTRODUCTION}

An electronic health record (EHR) is a longitudinal record of a patient's health information [10]. It may capture medical, surgical and procedural information, as well as family and social histories. Despite its potential to increase the effectiveness and efficiency in providing health care, IT adoption by the healthcare industry is sluggish. As of 2008 only $4 \%$ of physicians in ambulatory practice and $1.5 \%$ of hospitals reported using a fully functional EHR [7, 14].

To encourage the use of health information technology, Congress passed the HITECH Act, a component of the American Recovery and Reinvestment Act. To qualify for incentive payments from the Centers for Medicare and Medicaid Services (CMS), health care providers are required to meet stated Meaningful Use objectives at a specified measure of achievement. Providers who fail to achieve Meaningful Use requirements will receive decreased payments from CMS for clinical services beginning in 2015 and beyond. The earlier a health provider achieves the Meaningful Use objectives in its EHR system, the higher the incentive payment.

One criterion for Meaningful Use is to "maintain an active medication list." Active medication list (AML) is defined by the CMS as" A list of medications that a patient is currently taking." Substantial room for improvement in its accuracy exists. Research shows an inaccurate AML could have serious consequences affecting the patient's clinical outcome. Even though several studies identified contributing factors to errors in the collection of the AML on hospital admission, none of the sources we found focused on the elements inherent in the electronic health software. In this research, we explore the effect of human and information technology factors on the creation and the maintenance of an AML. In particular, our study attempts to address the following research questions:

1. What human factors affect the accuracy of active medication list $(A M L)$ ?

2. What information technology factors affect the accuracy of active medication list (AML)?

We adopted the case study approach to address the research questions. Briefly, the case study method is a research strategy that focuses on understanding the dynamics within a single environment. We investigate how the process of creating an AML is carried out in a hospital environment. This process was discovered by interviewing clinicians directly involved in the process and IT project managers responsible for the system development and maintenance.

We believe the results of this study will contribute to the academic and the applied communities. First, we expect to identify elements that affect the accuracy of the AML. Those elements will become constructs in our research model that can be further tested to advance theories in the field. Second, our study will inform clinicians and 


\section{Issues in Information Systems}

Volume 13, Issue 1, pp. 167-176, 2012

software engineers regarding what features of the system could lead to a more accurate AML. The guidelines proposed by this study can be adopted by the practitioners to address some system issues in software development.

The remainder of the paper is organized as follows: a literature review; our research methodology; a presentation of the research model and hypotheses, conclusions, and discussion of future research.

\section{LITERATURE REVIEW}

\section{Meaningful Use}

The 2009 HITECH Act continued the 2004 Executive Order to provide an EHR for every American by the year 2014. Under this provision, health care data will be captured in electronic format, increasing the accessibility and analysis of information, which will enhance the development of "evidence based practice." This should lead to improved patient safety and ultimately to improved health outcomes for individuals.

However, the HITECH Act will not allow for adoption of technology simply for the sake of technology, hence the need for Meaningful Use. Meaningful Use specifies the elements of "proof" in terms of reporting requirements that hospitals and eligible health care providers must follow to demonstrate their EHR system provides quality health care. Simply stated, EHRs must be implemented in such a way that they will improve health care.

In addition, the Meaningful Use criteria are used to certify the EHR systems from various vendors. It is hoped that this process of certification and incentives for adopting certified EHRs will lead to a standardization of function and data representation across EHR systems provided by vendors.

Two sets of Meaningful Use criteria and their associated measures exist. One set is for eligible professionals (e.g. M.D.s) and the other is for eligible hospitals. Each set has multiple elements that make up the criteria for that set. We present one objective and its measure directed to both groups. This objective is the subject of our research.

Eligible Hospital and CAH Meaningful Use Objective 4 and Its Measure [9]:

Objective: Maintain active medication list.

Measure: More than 80 percent of all unique patients admitted to the eligible hospital's or Critical Access Hospital's (CAH) inpatient or emergency department (POS 21 or 23) have at least one entry (or an indication that the patient is not currently prescribed any medication) recorded as structured data.

\section{Active Medication List}

We discovered studies on the active medication list focused on three broad areas - the accuracy of the medications listed, the clinician involved in gathering the data, and the source of the data.

First, a review of the literature on the accuracy of the AML on admission to the hospital shows substantial room for improvement. For starters, the definition of accuracy is subject to debate. Balon [1] identified accuracy as having the correct name, strength, route and frequency of administration. Others defined a break in accuracy if any difference between the medication use history and the admission medication orders occurred $[4,17]$ or if any discrepancy resulted in a medication order change [12].

Inaccuracies in the AML may be serious and affect patient outcomes. One study [4] found that nearly $56 \%$ of admitted patients had at least one unintended discrepancy between the AML and the medications ordered, $46 \%$ of those discrepancies being errors of omission. Furthermore, $48.6 \%$ of the discrepancies were judged to have the potential to cause moderate and severe discomfort or clinical deterioration. Gleason [12] reported errors originated from medication histories in $85 \%$ of patients, almost half of those errors being ones of omission. The results of inaccuracy of the AML may have serious consequences affecting the patient's clinical outcome. Gleason [12] identified the most common medication classes involved in errors to include cardiovascular agents, antidepressants, gastrointestinal agents, neurological agents and anti-diabetes medications 


\section{Issues in Information Systems}

Volume 13, Issue 1, pp. 167-176, 2012

Second, multiple clinicians assume the role as list taker at some point during the admission process. Balon [1] found this task is done by the emergency physician and an admitting nurse; Cornish [4] noted that this responsibility may fall to the admitting resident physician or medical student; Gleason [12] found pharmacists and hospital physicians take the home medication history. In fact, it is not unusual that role changes may occur when new technology is introduced [6].

Gleason [12] found that the clinician gathering the information for the AML, who may have time constraints and lack interview skills (is one of several factors influencing its accuracy.

Third, problems of accuracy may occur related to the information given by the List Source. Researchers mentioned that clinicians may have used one or a combination of sources to obtain the list of home medications, including patient/family interview, contacting outpatient pharmacies or the primary care physician. Gleason [12] mentions the use of multiple pharmacies by a patient, multiple prescribing physicians, and the patient/family as poor historians as factors affecting the accuracy of the AML. Cornish [4] acknowledges that patient illness or cognitive status, language barriers, or absence of a structured process to collect information may contribute to inaccuracies.

\section{Proposed Health Care Technology (HIT) Solutions to the Accuracy of Active Medication List}

A search of the directory of Certified Health IT Products list reveals that 392 EHR systems satisfy the Meaningful Use criterion for an AML. However, the meaningful use criterion does not specify accuracy as a measure. We find few references address the accuracy of AML. In general, there are three broad categories of solutions: patient centered, e-prescribing, and IT based reconciliation of medication lists.

\section{Patient Centered Solutions}

Walsh and Cussen [20] investigated what effect a ten minute medication review by a General Practitioner with a patient had on medication errors. They reported that inappropriate medications were detected in $54 \%$ of patients interviewed.

Schnipper et al. [19] reported the results of designing and implementing a patient portal into an EHR system. A medication module was designed to improve the accuracy of AML within the EHR. Based on usage and satisfaction data, patients felt it led to more accurate information about their AML for their health care provider.

\section{E-Prescribing Based Solutions}

Electronically prescribing medications (E-prescribing) has the advantage of electronically recording any medications prescribed for a patient. It is believed this process would lead to accurate AMLs. However, a case study of eight physician practices [5] and another case study of 24 physician practices [13] found that in the majority of the cases e-prescribing did not lead to an accurate AML. The patient's home medication list was not available or was unable to be reconciled with the medication list resulting from e-prescribing.

\section{Reconciliation of Mediation Lists Solutions}

Beckman et al. [2] propose a clinical decision support system (CDSS) to reconcile the various mediation lists (active or home medication list, in-patient medication list, and discharge medication list) associated with a patient. Although this design has not been implemented, it does reveal the complexity of a health information technology (HIT) solution to the problem of medication reconciliation. It illustrates that the solution to the accuracy of a patient's AML is complex and requires a deeper understanding of the causes of an inaccurate as well as an accurate AML.

\section{METHODOLOGY}

We found limited literature on the topic of active medication list. Therefore, we decided to conduct a case study to develop a theory we could empirically test later.

Case study is a research strategy that focuses on understanding the dynamics within single settings [18]. Eisenhardt's seminal paper [11] concludes that building theory using the case study approach is fruitful. She states case study is "especially appropriate in new topic areas" and "the resultant theory is often novel, testable, and 


\section{Issues in Information Systems}

Volume 13, Issue 1, pp. 167-176, 2012

empirically valid." Case study is used extensively in social science research such as sociology, history, management science, and education[18]. Even though in information systems research, case study is not as dominant as other empirical methods, such as experiments or surveys, its scientific nature and rigor have been extensively discussed and widely accepted $[3,15,8]$.

We chose a single-case design and selected a hospital (Hospital A) in the Midwest region from a fairly long list of potential hospitals due to its representation of size and type and its accessibility. Hospital A is a city-owned nonprofit acute care hospital with 140 beds. It admits about 6200 patients every year. It implemented EHR in 2004 and was considered an early adopter.

We collected data from three sources in the hospital. First were interviews with hospital staff in different capacities. We conducted interviews with a pharmacist, an admitting nurse, a nursing clinical informatics liaison, a project manager, a director of IT applications, and a hosptialist. All staff are highly educated and have many years of experience with EHR system in the hospital. Table 1 summarizes their positions, credentials, and experiences.

Table 1. Interviewee Information

\begin{tabular}{|l|l|l|l|}
\hline Current Job Title/Role & $\begin{array}{l}\text { Credential/ } \\
\text { Certification }\end{array}$ & $\begin{array}{l}\text { Number of } \\
\text { years in } \\
\text { current role }\end{array}$ & $\begin{array}{l}\text { Year started } \\
\text { working with } \\
\text { EHR under study }\end{array}$ \\
\hline $\begin{array}{l}\text { Pharmacist, Clinical } \\
\text { Coordinator }\end{array}$ & PharmD & 11 years & 2004 \\
\hline $\begin{array}{l}\text { Medical Director for the } \\
\text { Hospitalist Service }\end{array}$ & MD & 7 years & 2005 \\
\hline Admitting Nurse & RN & 4 years & 2004 \\
\hline Clinical Informatics Liaison & RN & 4 years & 2004 \\
\hline $\begin{array}{l}\text { Director, IT Application } \\
\text { Integration }\end{array}$ & MBA & 7 years & 2004 \\
\hline Project Manager & $\begin{array}{l}\text { MSN, RN-BC, } \\
\text { PMP }\end{array}$ & 9 years & 2003 \\
\hline Computer Education Specialist & MA, RN & 8 years & 2004 \\
\hline
\end{tabular}

Before we conducted the formal interview, we compiled a list of questions and conducted a pilot study with a pharmacist. We learned several lessons. First, some questions required rephrasing, and others needed to be removed or added. Second, in order for the interviewee to share information more thoroughly, we needed to send out the questions to the interviewee at least one day before the meeting. Third, we noticed it was easy to get sidetracked. So, great effort was needed to bring the interviewee back to the information that was directly related to our research questions. We recorded all interviews and used Dragon Naturally Speaking to transcribe the recordings into texts. To ensure the transcription was correct, the authors listened to the recording to summarize the key points.

The second data sources were the user manuals of the system. The authors gained insights from examining the writings and the screen shots of the system. The third data source was the system itself. The authors were given access to a mirror copy of the live system. We gained first-hand experience from logging into the system using different roles and navigating around the system.

Following Yin's guidelines [18], we adopted several measures to improve the reliability and the validity of the case study. We created a case study protocol and shared it among all the researchers. We developed a case study 


\section{Issues in Information Systems}

Volume 13, Issue 1, pp. 167-176, 2012

database to store and organize all case related materials such as notes, documents, and narratives. We acquired multiple sources of evidence through interviewing staff in different positions and examining the system independently. We had the key informants review our case study reports. In addition, we used pattern-matching and explanation-building, as specified by Yin [18], when we analyzed the data.

\section{RESEARCH MODEL AND HYPOTHESES}

Figure 1 below is our research model. For this study, we focus on five constructs: Active Medication List, List Taker, List Source, System Connectivity, and User Interface Design, and their relationships. We argue that four primary factors affect the accuracy of the AML: the person documenting the AML (List Taker), what sources are used (List Source), the connectivity of the EHR system with external databases (System Connectivity), and the user interfaces used to capture and present the AML (User Interface Design). The first two are human factors, and the last two are information technology factors. We detail the development of a research model below based on prior research and results of our case study.

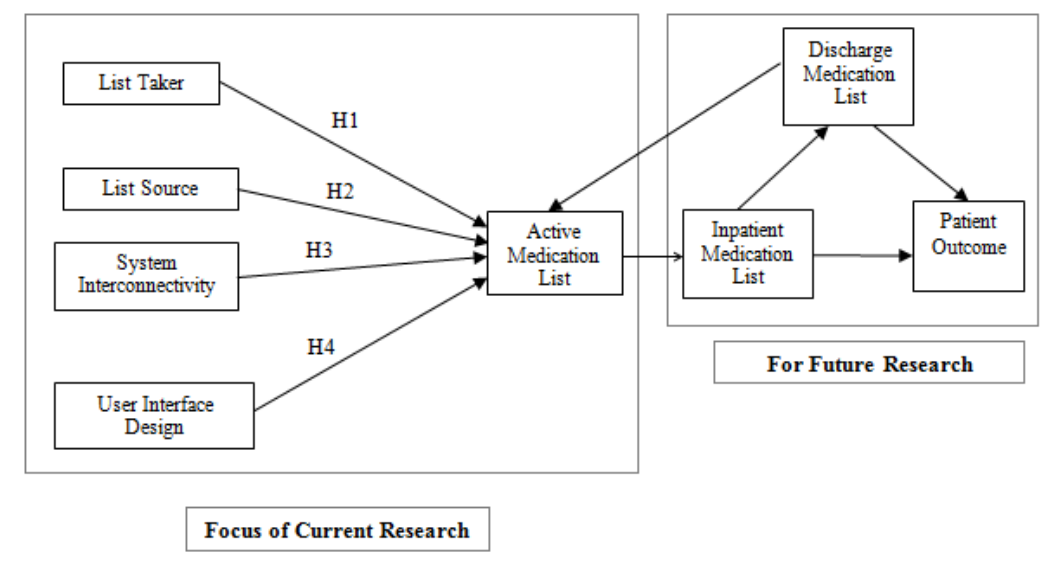

Figure 1. Research Model

\section{Active Medication List}

The Active Medication List, sometimes referred to as the list of home medications, may include prescription medications, over-the-counter (OTC) medications, herbal and supplemental products and "street" drugs. Two considerations of the AML are the medicines that are included and the accuracy with which those medications are documented. One important reason for accuracy is to continue medications during a hospital stay that the patient uses at home to treat chronic conditions. We have already seen issues related to accuracy and potential adverse patient outcomes from researchers [12, 1, 4].

However, the list of medications that should be included on the AML is open to debate. The pharmacist in our case study believes it should only include the medications the patient reports he/she is actually taking. This person makes the distinction between active and accurate.

"(The active medication list) ... in my perspective as a pharmacist, is what the patient is actually taking. Now a physician may argue that an accurate med list is what they have prescribed."

In this study, active medication list is defined as a list of medications that a patient is currently taking. This definition is in line with the one provided by the CMS. 


\section{Issues in Information Systems}

Volume 13, Issue 1, pp. 167-176, 2012

\section{List Taker}

The List Taker is defined as the clinician who documents the list of active medications (AML) of an individual patient in the health record. As mentioned in the Literature Review, other researchers revealed an assortment of list takers with responsibility for documenting the list of home medications.

Our case study also showed that multiple list takers compile the active medication list on admission. An Admission Nurse has initial responsibility to review the active medication list with a newly admitted patient. When the nurse is unable to get complete information of the patient's home medications (e.g., missing drug name, strength or frequency), an indication is made for the pharmacist to continue the information gathering until a more complete list is documented. If a patient is seen initially in the Emergency Department (ED), the process varies by time of day. During the night shift a clinical pharmacist is stationed in the ED and gathers the home medication list information. During other times, this list may be obtained by an emergency department nurse, emergency physician or the hospitalist.

Discussion about the clinician best suited to be the list taker is scant. In a study by Murphy [17] pharmacists were found to be "the ideal health professionals to obtain a medication history based on their education and experience with medications... and experience with patient medication interviews."

Likewise, our data shows the preference is for the pharmacist to collect the information for the AML. The pharmacist from our case study states,

"The pharmacists are the most accurate and trained health professional to obtain the medication list."

A reason for preferring the pharmacist as list taker is accuracy. A hospitalist in our case study, who uses the home medication listed as a reference when ordering inpatient medications, believes the pharmacist produces a more accurate home medication list in contrast to the information obtained by the nurse.

"When the nurses collected (the home medication list), it's not reliable. .

The pharmacists' information is much more accurate."

Even, the admitting nurse in our case study agrees that the pharmacist is best suited to be list taker:

"If I can't figure out the dosages ...pharmacy takes over and they will contact the patient's physician or pharmacy to get the accurate doses and list."

Lastly, the clinical informatics nurse liaison in our case study notes a preference for pharmacist being the list taker, but for an additional reason besides accuracy.

"Nurses, right or wrong, don't believe it's their responsibility. They think that they are starting the list or starting the capture and they don't feel ownership in the process. They know that the pharmacist or the pharmacy tech is going to go back and look up further information."

In discussion with the clinicians in our sample, the perception is that pharmacists have primary ownership in the collection of the active medication list and are more likely to produce an accurate AML. We asked each to rate the likelihood of an accurate AML using a Likert scale of 1- not at all accurate to 5- very accurate. Table 2 is the interviewee's ratings on the accuracy of AML when nurse and pharmacist as the list takers. 


\section{Issues in Information Systems}

Volume 13, Issue 1, pp. 167-176, 2012

Table 2. Interviewee Ratings on Accuracy and List Takers

\begin{tabular}{|l|c|c|c|c|}
\hline List Taker & $\begin{array}{l}\text { Hospitalist } \\
\text { rating }\end{array}$ & $\begin{array}{l}\text { Admitting Nurse } \\
\text { rating }\end{array}$ & $\begin{array}{l}\text { Pharmacist } \\
\text { rating }\end{array}$ & $\begin{array}{l}\text { Clinical Informatics } \\
\text { Nurse Liaison rating }\end{array}$ \\
\hline $\begin{array}{l}\text { Accuracy when Admitting } \\
\text { Nurse is List Taker }\end{array}$ & 2 & 3 & 2 & 2 \\
\hline $\begin{array}{l}\text { Accuracy when Pharmacist } \\
\text { is List Taker }\end{array}$ & 5 & 5 & 5 & 5 \\
\hline
\end{tabular}

Therefore, we hypothesize the following relationship between list taker and AML:

H1: Among the list takers, clinical pharmacists produce the most accurate AML.

\section{List Source}

List Source is the person or object that provides the information about the home medications. Multiple sources of information may be consulted by the List Taker [12,4]. Our Case Study revealed List Takers may use any of the following list sources.: 1) Consult with the patient, a family member or caregiver, 2) Review a paper list of medications provided by the patient/family, 3) Examine medication containers brought in by the patient, 4) Look up an electronic list from a previous admission viewable on the electronic health record, 5) Contact the patient's primary care provider, or 6) Contact the patient's retail pharmacy.

Problems of accuracy may occur related to the information given by the List Source [12]. List Sources in our study produced similar problems. For example, the hospitalist in our Case Study mentioned that patients themselves may be barriers,

"If I'm asking for a med history... in the ER, ...the patient or the person who is in there with them will be very annoyed if I start asking 'What medications are you on and what's the dosage?' They say, 'You already have that information, the nurses have already gathered that information."”

The clinical informatics nurse liaison agreed that the patient as List Source may be problematic.

"(Patients) may even have a piece of paper with them with their medication written down. But often times it is out of date (and) we have the patient as being a barrier to a successful medication history."

The pharmacist noted that even the primary physician's list may be inaccurate as a source of information

"(The) on-call physician may call something in on a weekend that never makes it to the (clinic) chart or (the patient) can get samples (that are not captured in the clinic record.)"

We found gaps exist in the list of home medication when only one source of List Source was used. Therefore, we hypothesize the following relationship between list sources and AML:

$\mathrm{H} 2$ : When a combination of List Sources is used, a more accurate AML is compiled.

\section{System Connectivity}

System connectivity is a feature of an EHR system that implements access to external databases of patient information. These external databases would be maintained in: retail pharmacies; doctor offices (PCP, Specialists, 


\section{Issues in Information Systems}

Volume 13, Issue 1, pp. 167-176, 2012

DDSs, DOs, ODs, et al); health insurance provider's databases; and third party medication information repositories (e.g. SureScripts-RxHub - a national network for the exchange of prescription data between physicians, pharmacies, and health insurance providers). Researchers have found the reconciliation of AML with external lists may improve accuracy of the AML [1].

When asked if system connectivity would increase the accuracy of the AML the participants in our case study responded as follows:

A pharmacist from our case study stated:

“... a centralized server/database of all information being connected and shared would help."

The Director of IT Application Integration reported the capability:

"... to access SureScripts-RxHub to help verify medication list entries".

The Clinical Informatics Liaison's response was:

“... we do also have a function of the system call Get RXHistory and that is a tool that we have purchased a license for and based on whether or not the patient's pharmacy is participating and the insurance company is participating we can pull historical data related to the patient filling prescriptions. It does not record whether or not the patient's physician wrote a prescription but whether or not one was filled. We have high hopes about that system being a great tool for us and checking the accuracy of the patient's active medication list"

These quotes and similar ones lead to the research model's hypothesis with respect to the relationship between system connectivity and active medication list:

\section{H3: System connection to external patient medication list databases increases the accuracy of the AML.}

\section{User Interface Design}

The user interface is designed to facilitate the collection of medication information from the patient. In addition, the design should allow for the verification of the information that is collected. Any component of the design that detracts from the ease of information collection or verification of the information or allows for the collection of ambiguous information is considered a design component that detracts from the EHR's usability. For an overview of EHR usability see [21] or [16].

Our review of the EHR application used in our case study for creation of the AML revealed the presence of free text fields for data entry. Free text fields allow entry of data that is not formatted to standard use. As a result the data will not be edited data. This could lead to inaccuracies.

Our concern was substantiated by the following remark from the pharmacist:

"...one of the things we're running into now with e-prescribing, a lot of the physicians will say "see instructions." "See instructions" flows to a free text field and none of that free text field is ever going to convert over to real orders without somebody reentering that information. And, again, every time you touch a medication order, there's always a potential for error so that can lead to inaccuracies ..."

Again, our review of the EHR application used in our case study for creation of the AML revealed the presence of unused fields for data entry. Unused fields can allow for ambiguous data entry that may lead to inaccuracies.

Our concern was substantiated when the computer education specialist responsible for the training of staff on this application acknowledged there are several unused fields on the data collection form for the AML.

When asked how that situation was handled in the training of new users of the application the computer education specialist instructed new users: 


\section{Issues in Information Systems}

Volume 13, Issue 1, pp. 167-176, 2012

“... to ignore the unnecessary fields".

In addition she stated:

"... the active medication list application is a modification of pre-existing order entry application".

This explained the unnecessary date entry fields.

The issues of free text fields and unnecessary data entry filed leads to the research model's hypotheses with respect to the relationship between user interface design and active medication list:

H4: A user interface designed solely for the purpose of collecting and recording a patient's AML will increase the likelihood of an accurate AML

\section{CONCLUSIONS AND FUTURE RESEARCH}

In this study, we provided a thorough review of the literature regarding active medication list. Since findings from prior research are limited, we conducted a case study in Hospital A to develop a theory we could empirically test later.

From the case study, we gathered data from three sources: interviews, user manuals, and our own examination of the EHR system. We developed a research model that primarily focused on five constructs and their relationships. We argue that among all the list takers, pharmacists will generate the most accurate AML. We also state that the more sources that are used, the more accurate the AML will be. Besides the above human factors, we also identified two technology factors: system connectivity and user interface design. We hypothesize system connection to external databases will lead to an accurate AML, and user interfaces designed solely for the medication list will improve the accuracy of the AML.

There are several areas for future research. We will propose a more comprehensive research model and empirically test the model through methods such as survey, or experiment. In addition to the AML, we will also investigate other criteria for Meaningful Use.

\section{REFERENCES}

1. Balon, J. \& Thomas, S. A. (2011). Comparison of Hospital Admission Medication Lists With Primary Care Physician and Outpatient Pharmacy Lists. Journal of Nursing Scholarship, 43(3), 292-300.

2. Beckman, L., Bleil,G., Fernandes, H., Nelson, L., \& Rothschild, J. (2010). Clinical Decision Support Systems Enabling Medication Reconciliation. Medinf 406 Clinical Decision Support Northwestern University. Available: http://www.grbleil.com/uploads/5/6/6/5/5665684/406_paper_medication_reconciliation.pdf.

3. Benbasat, I., Goldstein, D. K., \& Mead, M. (1987). The Case Research Strategy in Studies of Information Systems. MIS quarterly, 369-386.

4. Cornish, P. L., Knowles S. R., Marchesano, R., Tam, V.,Shadowitz, S., Juurlink, D. N., \& Etchells, E. E. (2005). Unintended Medication Discrepancies at the Time of Hospital Admission. Archives of Internal Medicine, 165, 424-429.

5. Crosson, J. C., Schueth, A. J., Isaacson, N., \& Bell, D. S. (2012). Early Adopters of Electronic Prescribing Struggle to Make Meaningful Use of Formulary Checks and Medication History Documentation. Journal of American Board Family Medicine, 25(1), 24-32.

6. Davidson, E. J.\& Chismar, W.G. (2007). The Interaction of Institutionally Triggered and Technology-Triggered Social Structure Change: An Investigation of Computerized Physician Order Entry. MIS Quarterly, 31(4), 739758.

7. Desroches, C.M., Campbell, E.G., et al. (2008). Electronic Health Records in Ambulatory Care- A National Survey of Physicians. New England Journal of Medicine, 359, 50-60. 


\section{Issues in Information Systems}

Volume 13, Issue 1, pp. 167-176, 2012

8. Dubé, L., \& Paré, G. (2003). Rigor in Information Systems Positivist Case Research: Current Practices, Trends, and Recommendations. MIS quarterly, 27(4), 597-636.

9. EHR Incentive Programs - Hospitals. (2012). Available: https://www.cms.gov/EHRIncentivePrograms/Downloads/Hosp_CAH_MU-TOC.pdf, Accessed February 6, 2012.

10. EHR Overview. (2012). Available: http://www.ncrr.nih.gov/publications/informatics/ehr.pdf, Accessed February 6, 2012.

11. Eisenhardt, K. M. (1989) Building Theories from Case Study Research, Academy of management review, 14, 4, 532-550.

12. Gleason, K. M., McDaniel, M. R., Feinglass, J., Baker, D. W., Lindquist, L., Liss, D., \& Noskin, G.A. (2009). Results of the Medications At Transitions and Clinical Handoffs (MATCH) Study: An Analysis of Medication Reconciliation Errors and Risk Factors at Hospital Admission. Journal of General Internal Medicine, 25(5), 441-447.

13. Grossman, J.M., Boukus, E.R., Cross, D.A., \& Cohen, G.R. (2011). Physician Practices, E-Prescribing and Accessing Information to Improve Prescribing Decisions. Center for Studying Health System Change.

14. Jha, A.K., DesRoches, C.M., et al. (2009.) Use of Electronic Health Records in U.S. Hospitals. New England Journal of Medicine, 360, 1628-38.

15. Lee, A. S. (1989). A Scientific Methodology for MIS Case Studies. MIS quarterly, 33-50.

16. Lowry, S. Z., Quinn, M. T., Ramaiah, M., Schumacher, E. R., Patterson, M. S., North, R., Jiajie, Z., Gibbons, M. C., \& Abbott, P. (2012). NISTIR 7804: Technical Evaluation, Testing, and Validation of the Usability of Electronic Health Records. U.S. Department of Commerce, National Institute of Standards, February 2012

17. Murphy, E.M., Oxencis, C.J., Klauck, J.A., Meyer, D.A., \& Zimmerman, J.M. (2009). Medication Reconciliation at An Academic Medical Center: Implementation of A Comprehensive Program from Admission to Discharge, American Journal of Health-System Pharmacy, 66(23), 2126-31.

18. Yin, R. K. (2003). Case Study Research: Design and Methods. Sage Publications, Thousand Oaks, USA.

19. Schnipper, J. L.,Gandhi, T. K., Wald, J. S., Grant, R. W., Poon, E. G., Volk, L. A., Businger, A., Siteman, E., Buckel, L., \& Middleton, B. (2008). Design and Implementation of a Web-Based Patient Portal Linked to an Electronic Health Record Designed to Improve Medication Safety: The Patient Gateway Medications Module, Informatics in Primary Care, 16(2), 147-155.

20. Walsh, E.K. \& Cussen, K. (2010). Take Ten Minutes: A Dedicated Ten Minute Medication Review Reduces Polypharmacy in the Elderly. Irish Medical Journal, 103(8), 236-8.

21. Zhang, J., \& Walji, M. (2011). TURF: Toward a Unified Fame work of EHR Usability. Journal of Biomedical Informatics, 44 (6), 1056-1067. 